\title{
The Tangible Map Exhibit
}
Matt Dooley
Jake Coolidge
University of Wisconsin-River Falls
mathew.dooley@uwrf.edu
Colorado State University
ackecoolidge@gmail.com

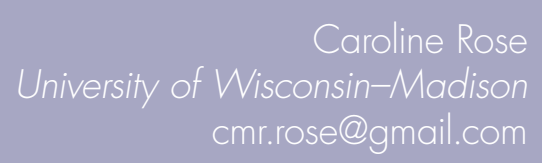

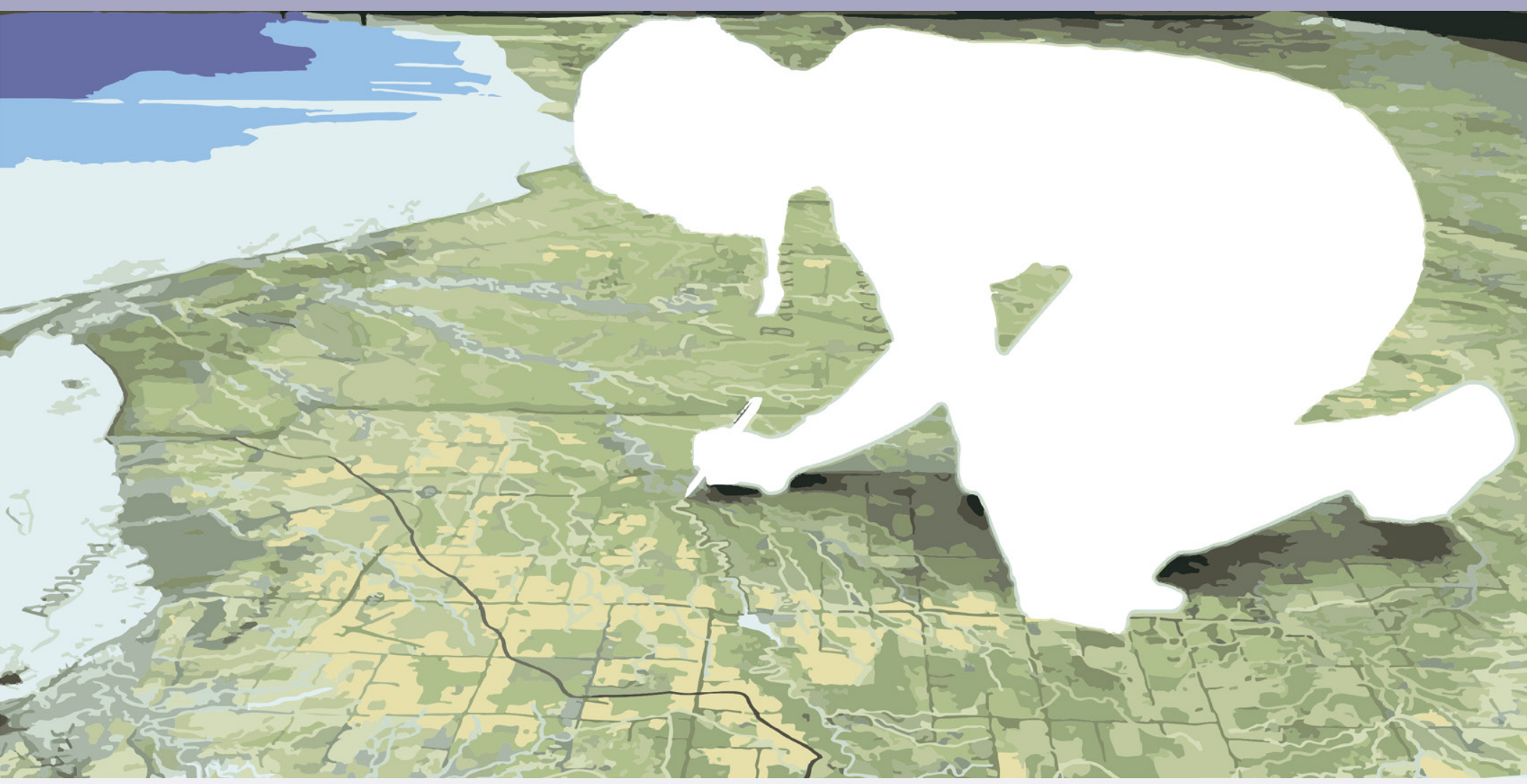

The Tangible Map Exhibit highlighted the importance of tangible, physical works in modern cartography and celebrated visually stunning, artistic maps created by contemporary makers. The exhibit was a part of the Map Gallery at the 2015 NACIS Annual Meeting in Minneapolis, Minnesota, which was open to the public for the first time ever. It featured over fifteen works created by more than a dozen cartographers across North America and beyond.

TANGIBLE, PHYSICAL MAPS continue to play an important role in contemporary cartography. They provide a platform for investigation, an outlet for creative expression, and help break down barriers to access. Tangible works also provide a means to inform digital design in ways that honor deeply rooted traditions in cartography. They complement, rather than counter, digital cartography, as many of these pieces were made leveraging digital tools by makers who are proficient using current technologies.

Tangible interactions between maker, place, and medium enhance our understanding of the environment and can facilitate a reverence for the places being represented.
Through a process of slowing, stopping, observing, experiencing, and contemplating, a maker can engage in a thoughtful and intentional mapping practice that is sensitive to interconnectedness and strives for a non-objectified relationship with place. Working in a physical medium also provides an outlet for creative expression. By making in a new, unfamiliar medium, we can create judgment-free spaces that allow for experimentation, risk-taking, and the unexpected.

Likewise, physical media encourage tangible interactions between users and maps. This allows mapmakers to engage with a larger audience, and in some cases, help create 
open public platforms where multiple voices can be heard. Similarly, physical works might offer an invitation to play, explore, or to expose our current relationship with natural systems. By introducing ambiguity through omission, manipulation, or by re-imagining spatial relationships, we offer room for multiple interpretations and create environments where different explanations and perceived meanings are seen as legitimate.

Perhaps most importantly, digital products continue to be inaccessible to significant portions of the population. Tangible maps, such as tactile maps for the blind, provide access for people without digital toolsets and challenge a visual bias in cartographic design. Other formats, such as kiosk maps, put relevant information in direct public view, therefore functioning as a political agent.

While varied in content, approach, and media, these works attest to the dedication, tenacity, and thoughtfulness of NACIS members and others who create tangible work that speaks to the continued relevance of physical media in contemporary cartographic practice.

For full maker statements, as well as additional media, visit tangiblemapexhibit.blogspot.com.

\section{THE WESTERN SHORE OF LAKE MICHIGAN AND ENVIRONS}

Jake Coolidge. 2015. Ink and graphite on paper. $15 " \times 60 "$.

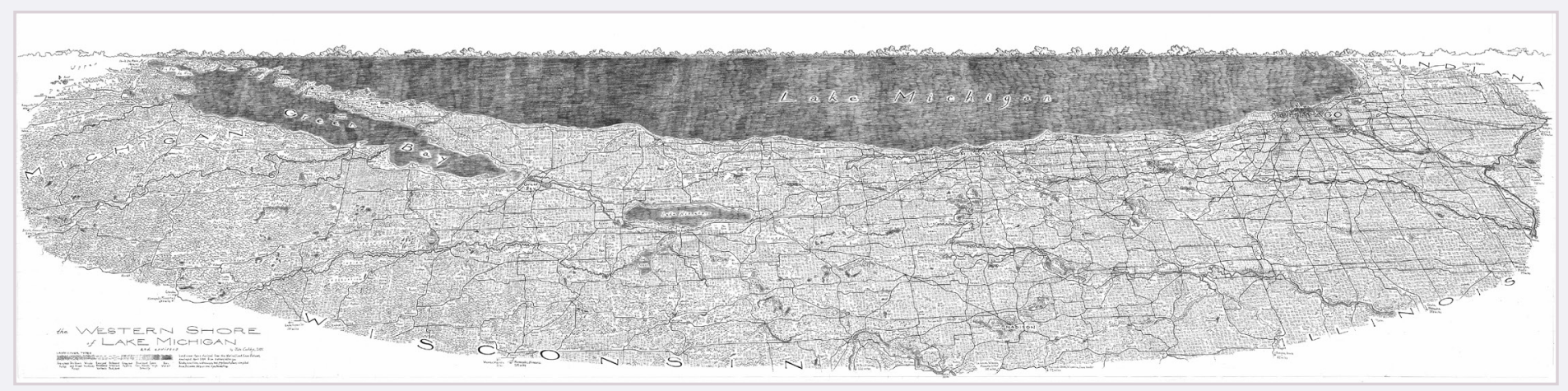

"I create maps by hand that invite viewers to consider the expressive capabilities of maps and the hand of the cartographer in shaping their visual outcomes. All maps, however produced, are human creations and should be engaged with and interrogated accordingly."

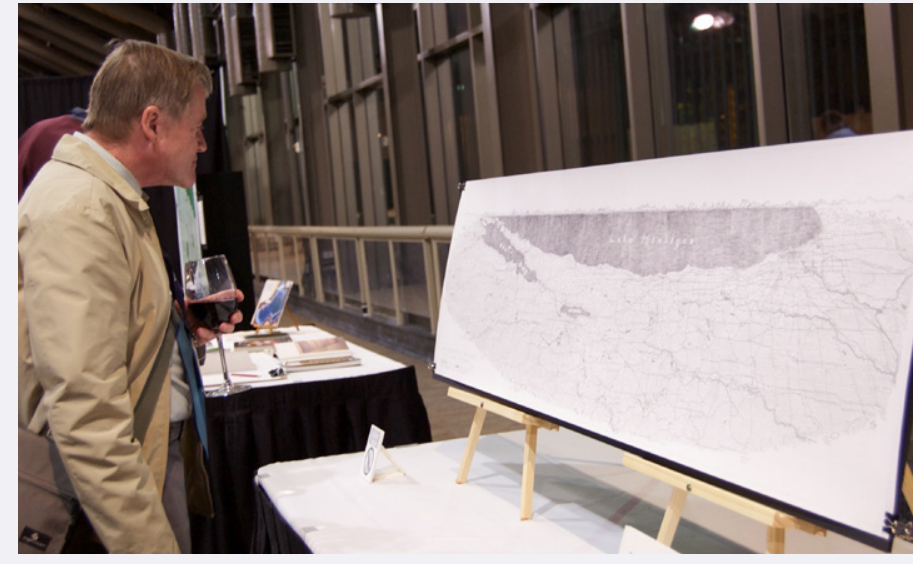

Photo by Dylan Moriarty

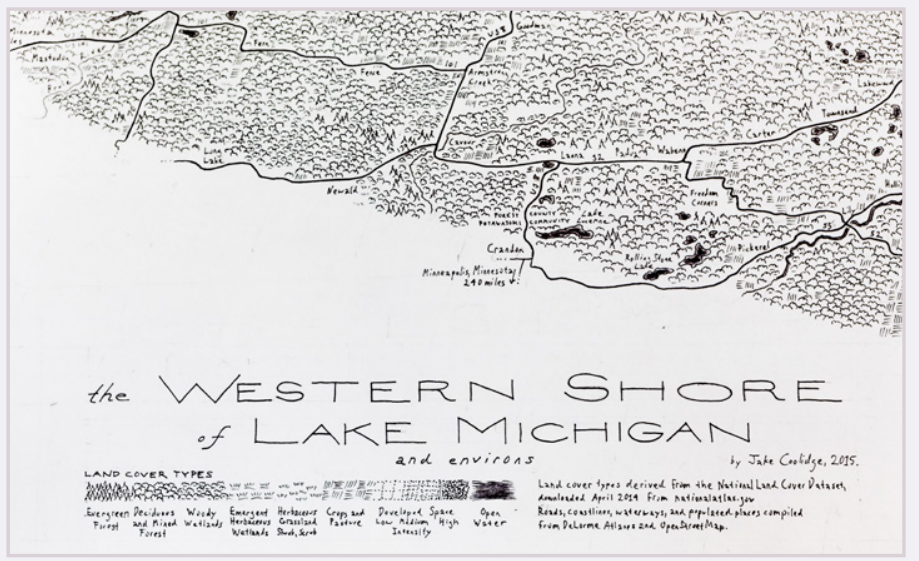

Photo by Charles P. Rader 


\section{BAD RIVER-WETLAND MEDICINE RIVER: INTERACTIVE FLOOR MAP}

Jessie Conaway with the Bad River Band of Lake Superior Ojibwe. 2015. Printed vinyl. 20'×30'.

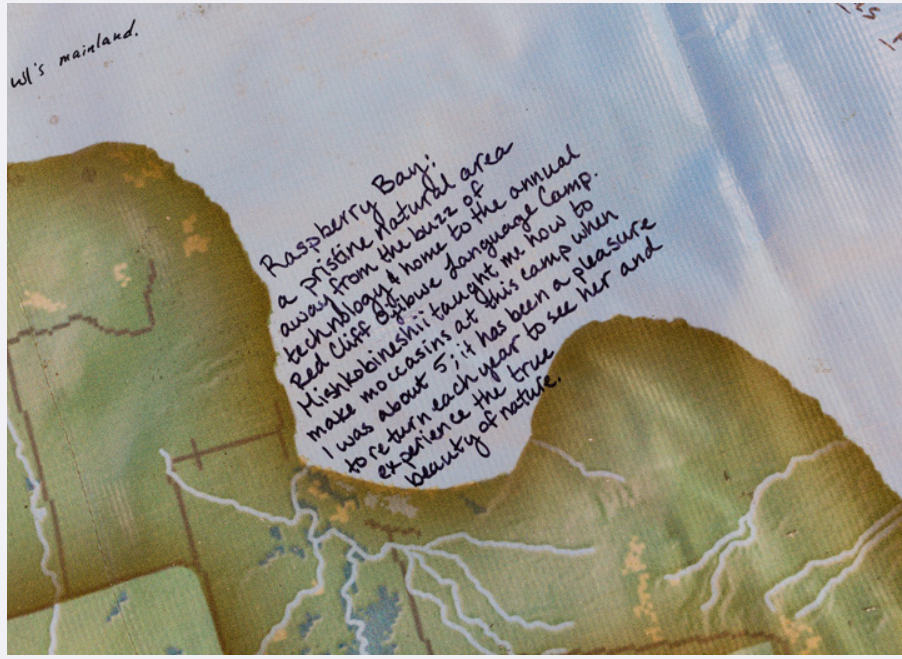

“... the floor map is an open public platform. Map contributors hold water features and indigenous voices front and center. We represent water vibrantly. Storymapping honors Ojibwe traditions of the educational and cultural values of storytelling. Participatory mapping assuring that many voices are represented."

Photo by Charles P. Rader
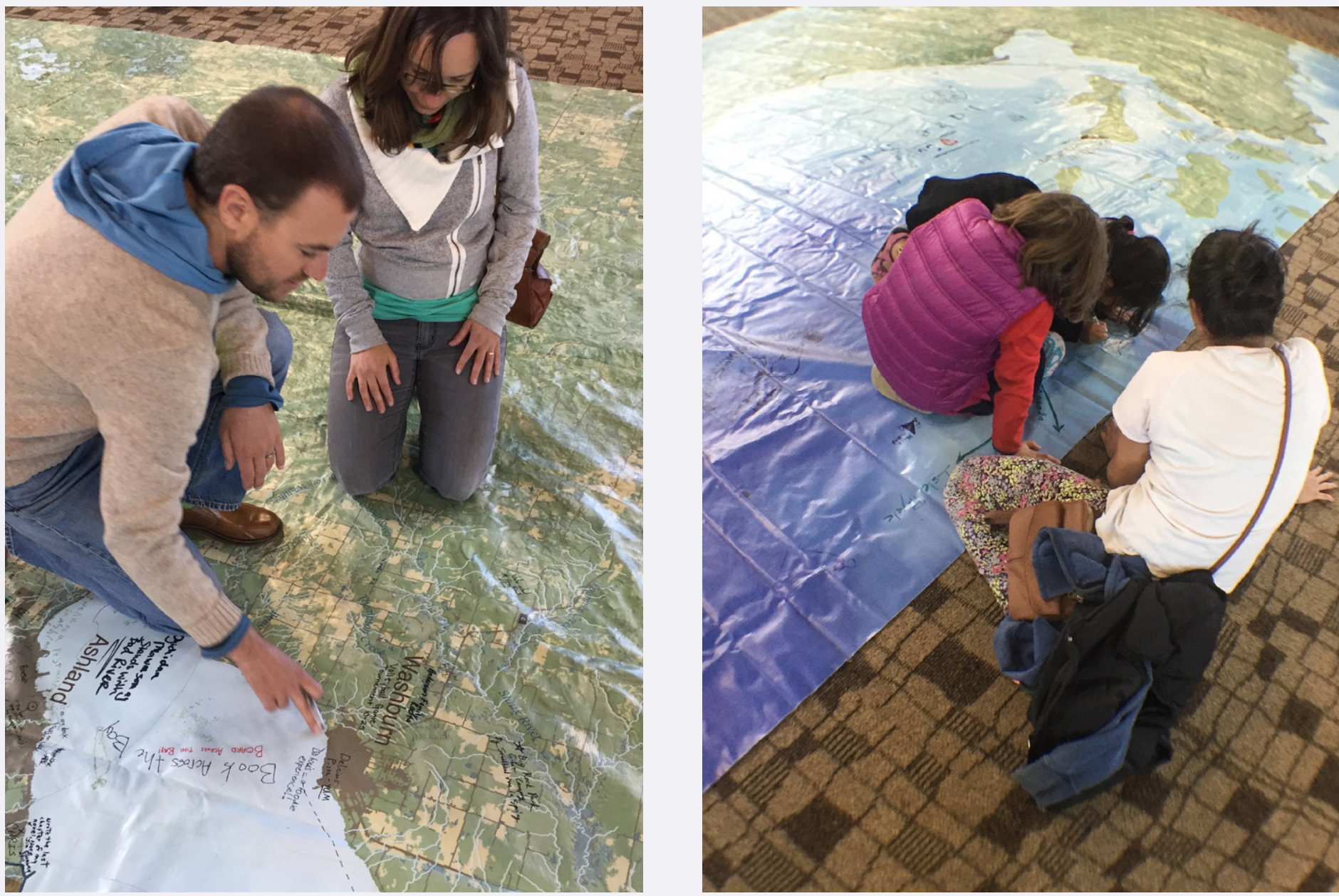

Photo by Matt Dooley

Photo by Matt Dooley 


\section{TRACES I}

Jeannine Kitzhaber. 2015. Mixed media on canvas. 48"×72"×3".

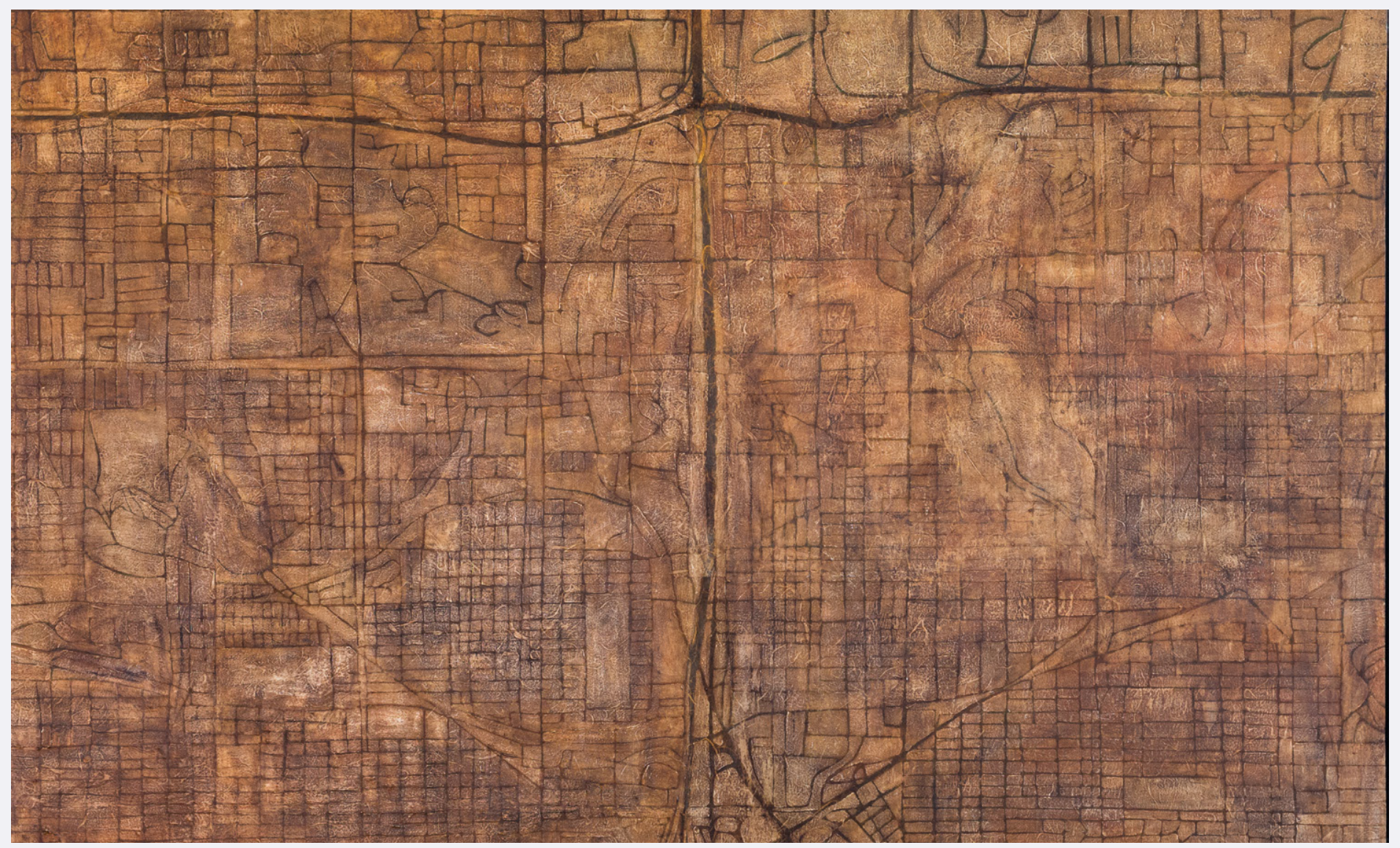

Photo by Charles P. Rader

"While commuting for my job, I began a tangible journal of my travels as a way to make sense of my busy workday and to chronicle the ever-changing landscape."

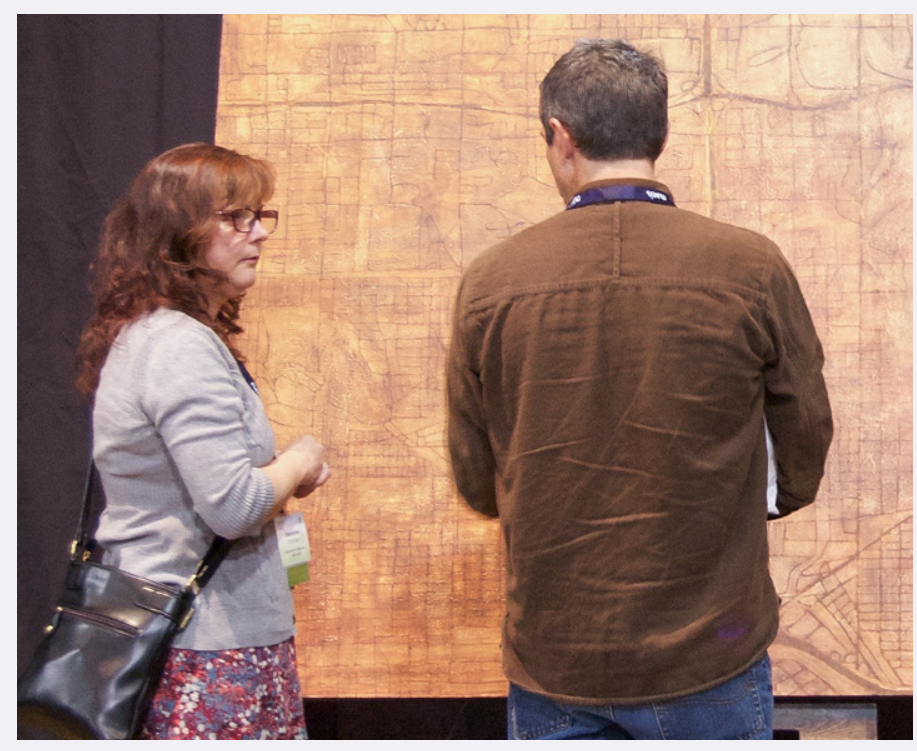

Photo by Dylan Moriarty

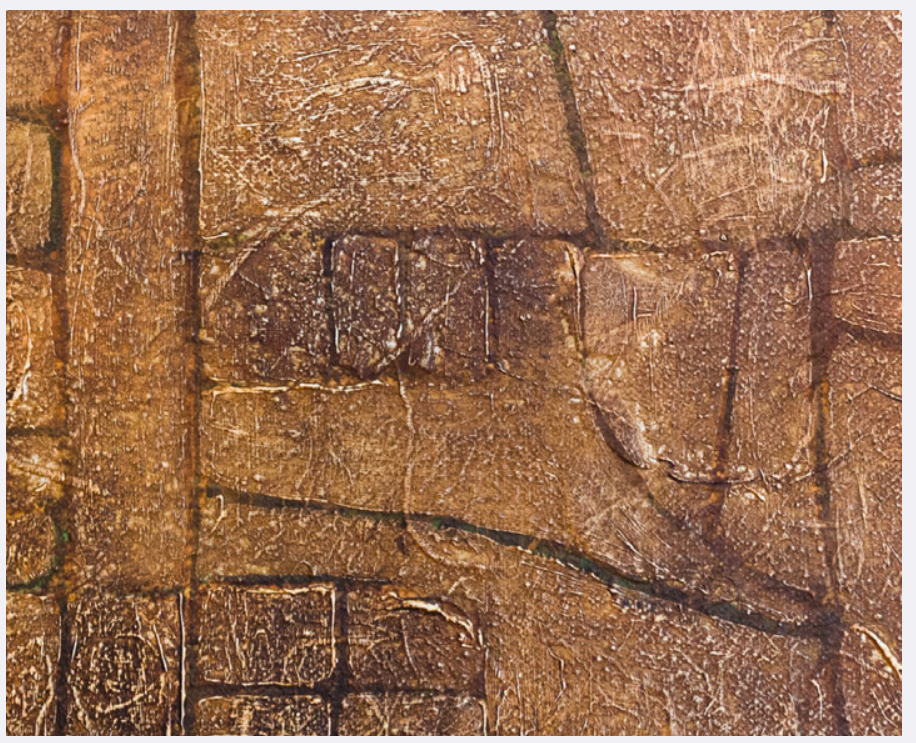

Photo by Charles P. Rader 


\section{TACTILE MAP SYMBOLS ACROSS THREE MEDIA}

Megen Brittell, Amy Lobben, Megan Lawrence, and Manny Garcia. 2015. 3D printing, microcapsule paper, embossed paper. Multiple sizes.

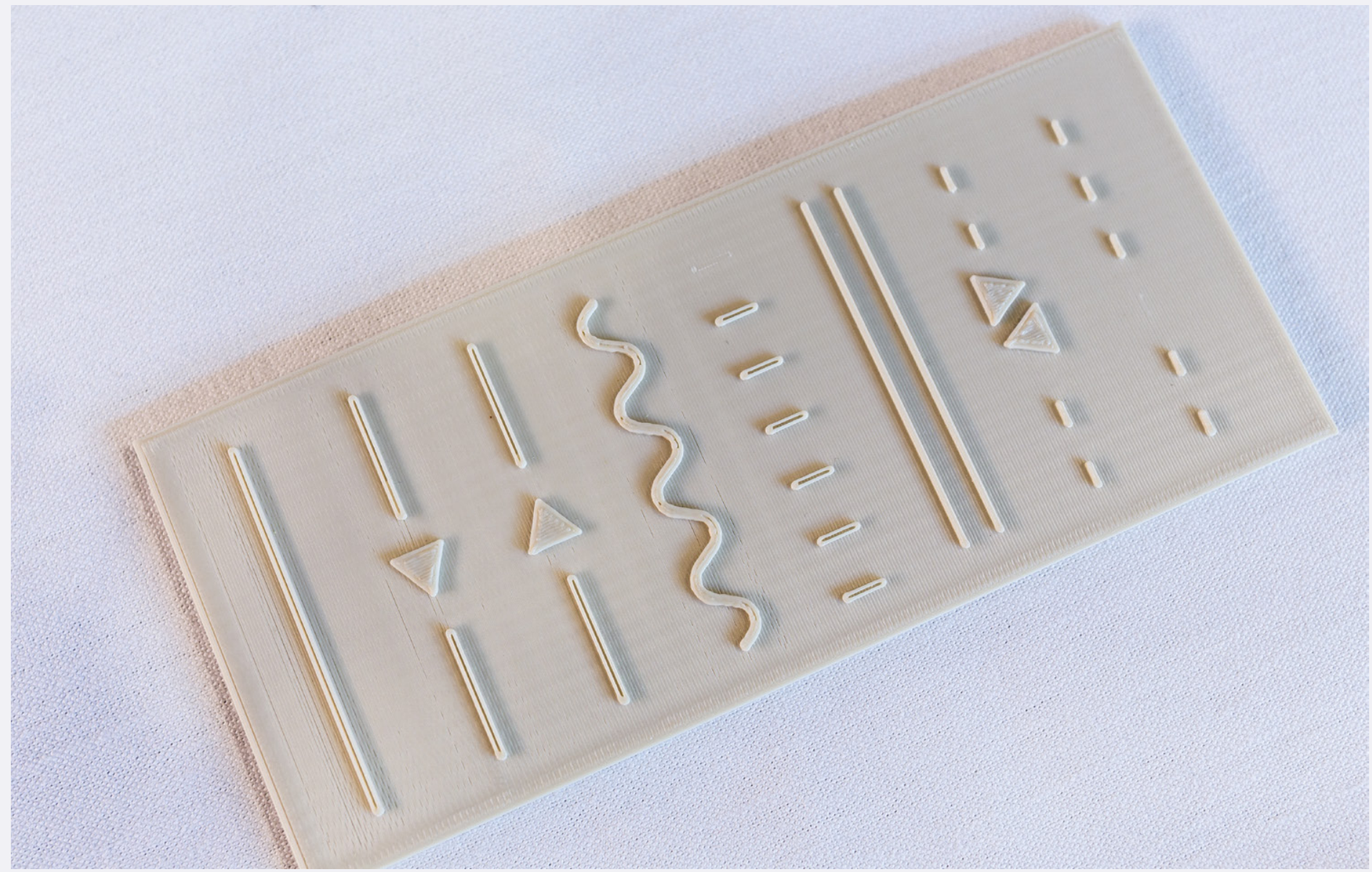

Photo by Charles P. Rader

"A visual bias in cartographic design has rendered many maps and the information they contain inaccessible to people with visual disabilities. Tactile maps provide one mechanism by which to address the need to make maps and geospatial data more accessible.”

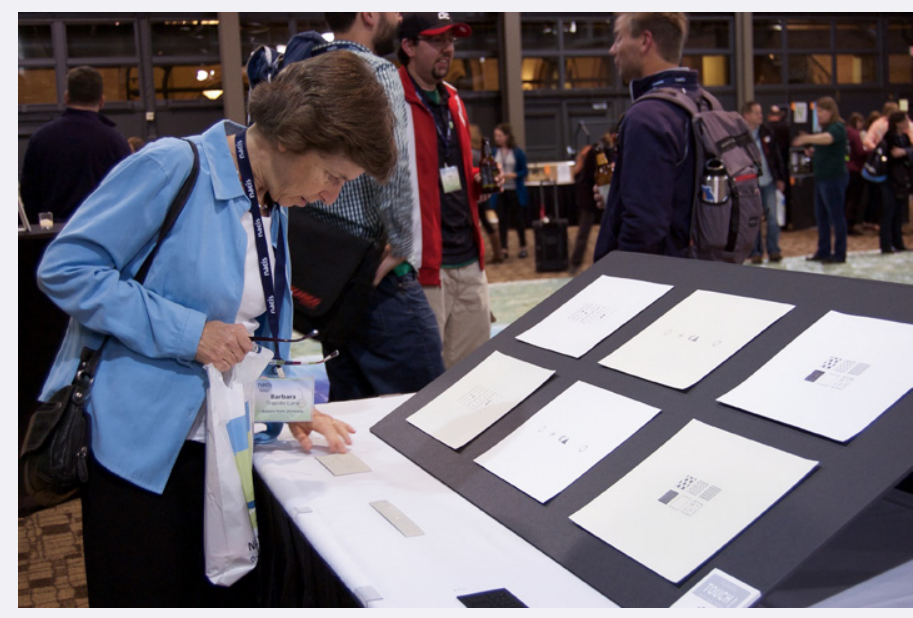

Photo by Dylan Moriarty

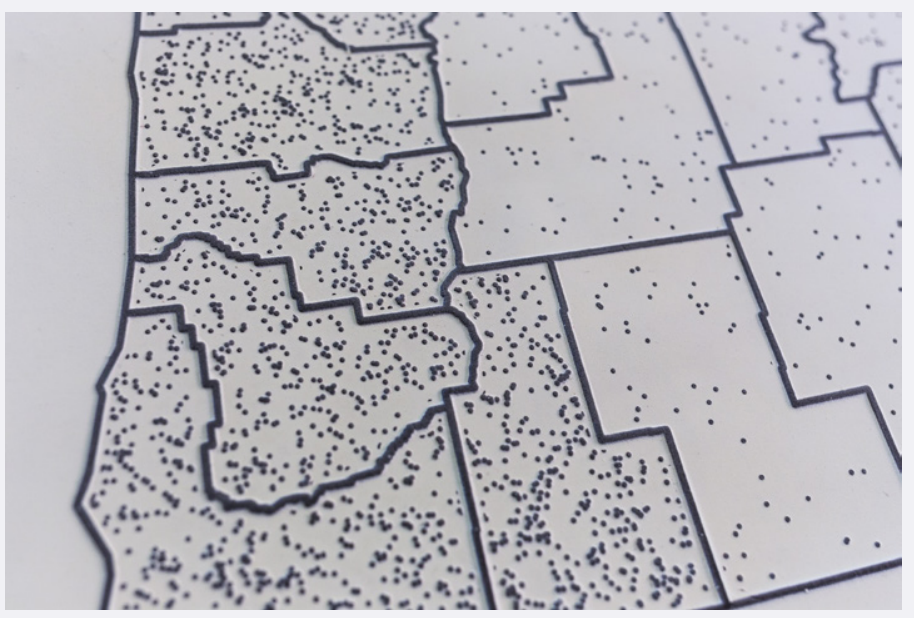

Photo by Charles P. Rader 
Steven R. Holloway. 2015. A suite of two artist-editioned lithographs. Ea. 40"×30", ed. of 7 .

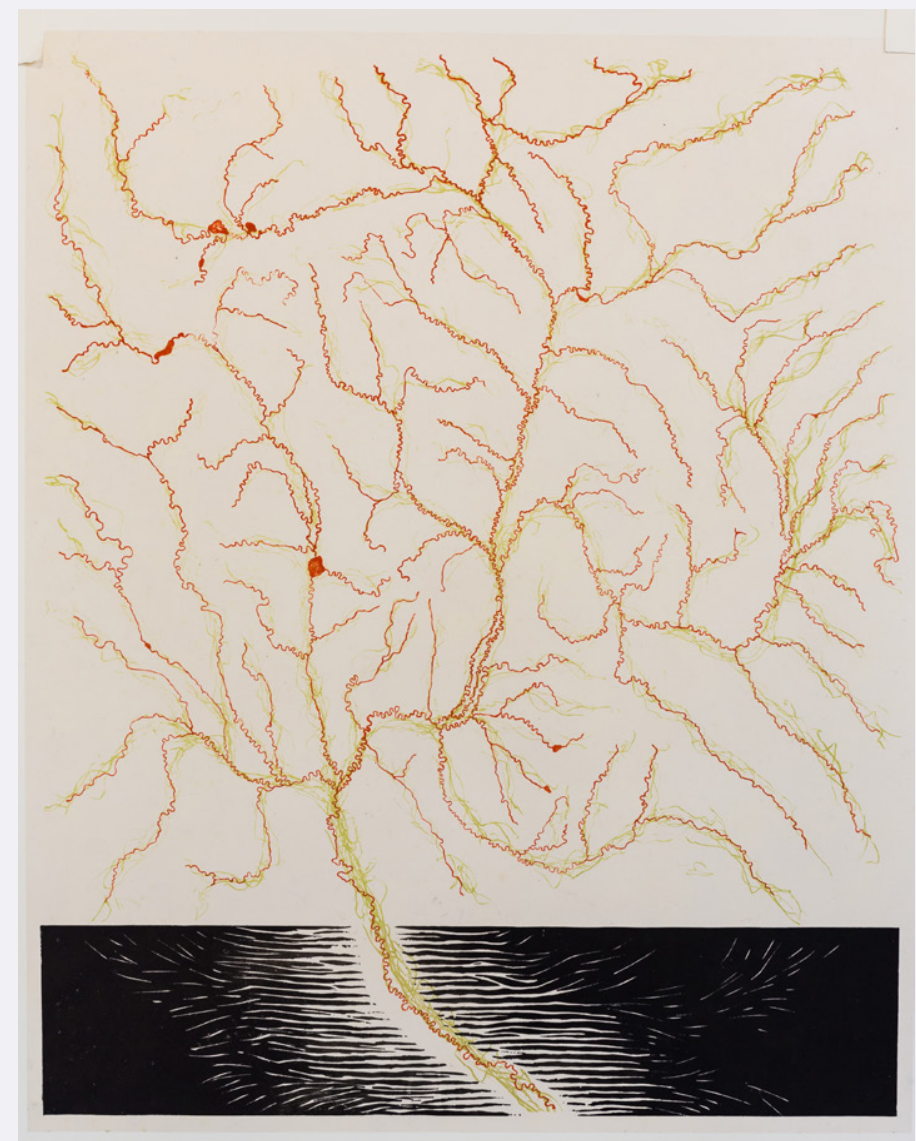

Photo by Charles P. Rader

"I stop, and observe and experience the place, the other. Stopping is, it turns out, difficult and takes a great deal of patience and practice. How do you stop? There are many ways but they all involve effort and practice. And really good stopping means making many many efforts, repeated over and over until you have entered into and experienced the place itself. And felt and enjoyed and got wet and dirty and cold and sun cloud water exposed. Then make a response."

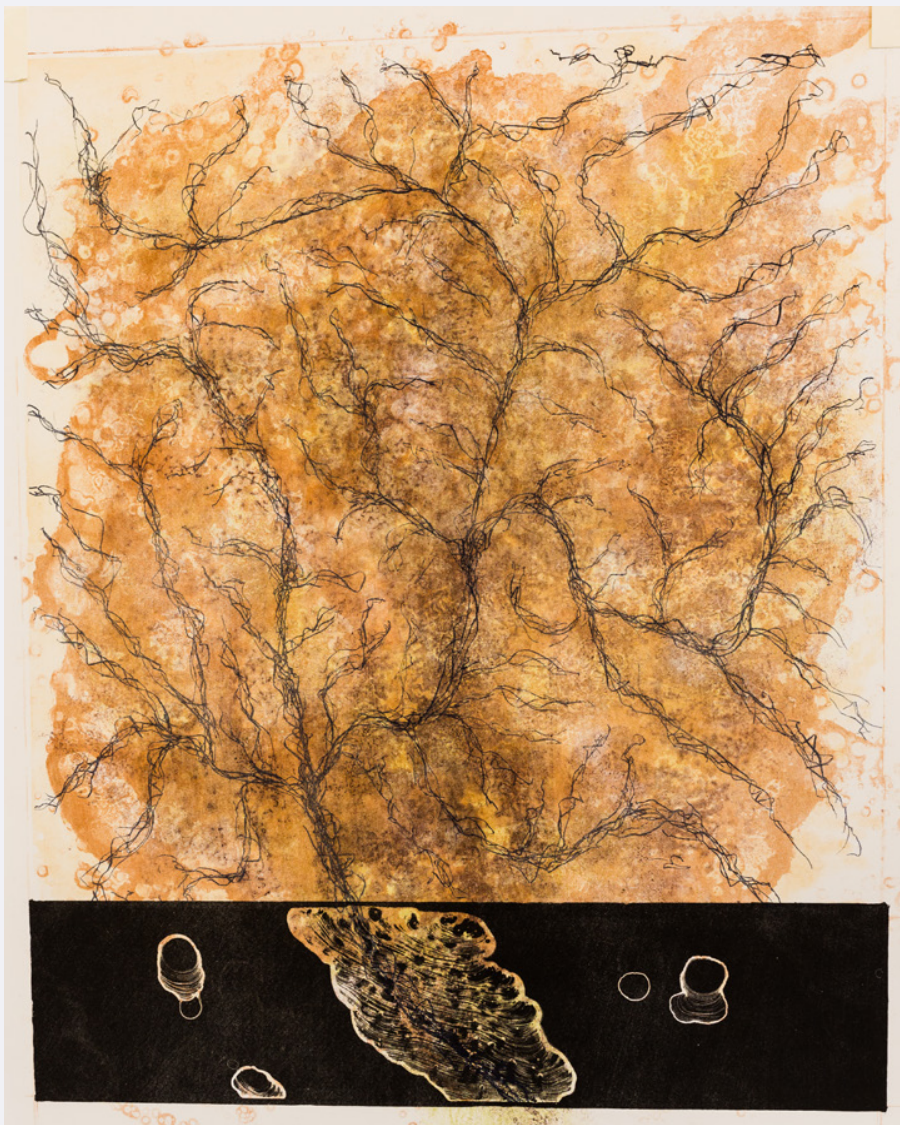

Photo by Charles P. Rader

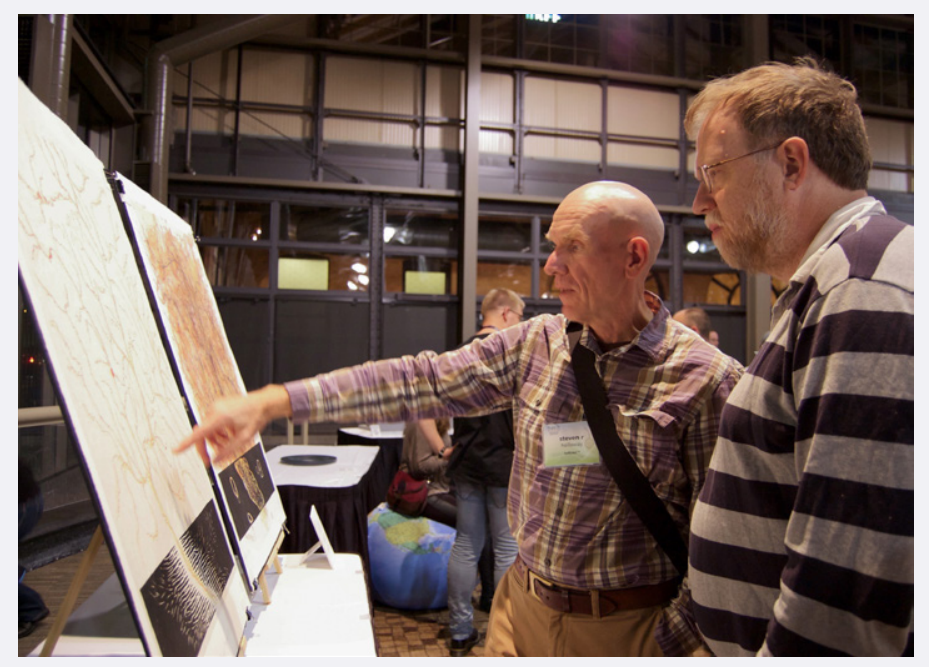

Photo by Dylan Moriarty 


\section{BATHYMETRIC BOOK}

Caroline Rose. 2012-Present. $1^{\text {st }}$ Edition: inkjet printing and blue paint on paper, Japanese stab binding. $2^{\text {nd }}$ and $3^{\text {rd }}$ prototypes: laser-cut paper in a Coptic binding, magnet closure. $8.5 " \times 5.5 " \times 0.5 "$.

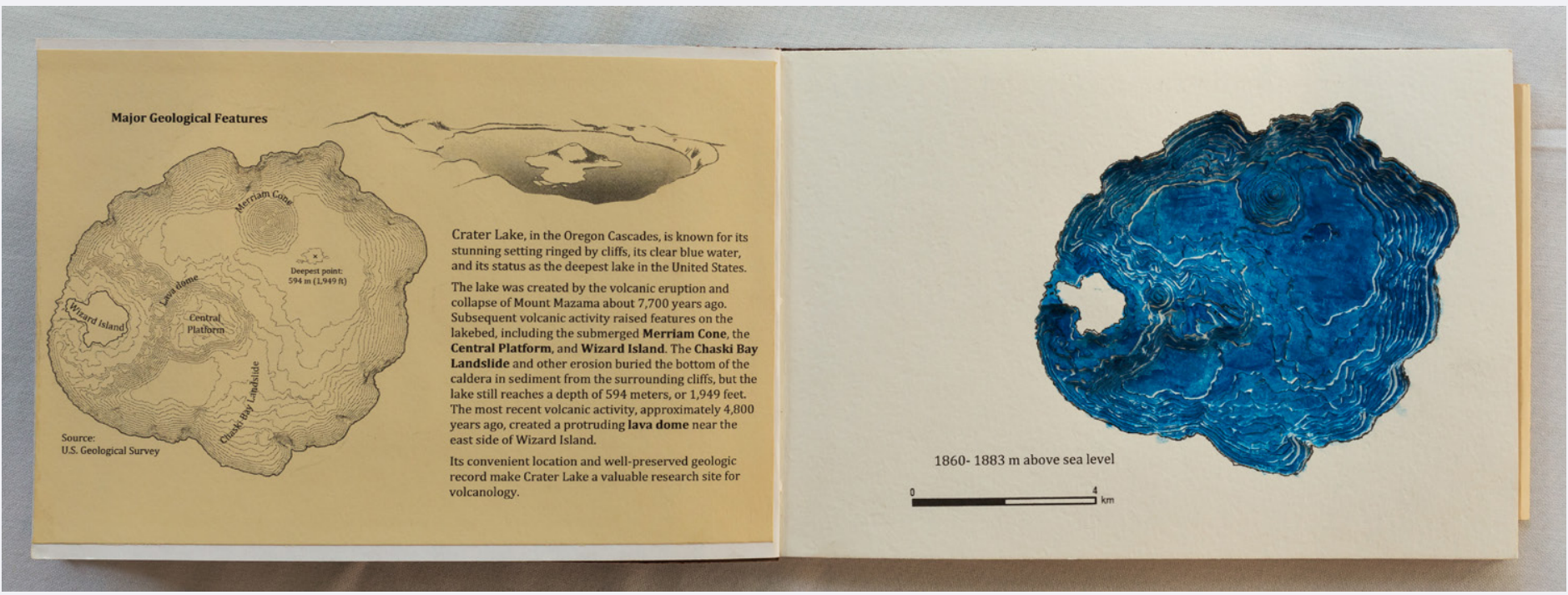

Photo by Charles P. Rader

"I hope that the reader will be prompted to 'look below the surface,' thinking about the processes that form a physical landscape, contemplating how unseen dimensions of the lake are revealed by scientific study, and feeling inspired to visit fascinating places like Crater Lake.”
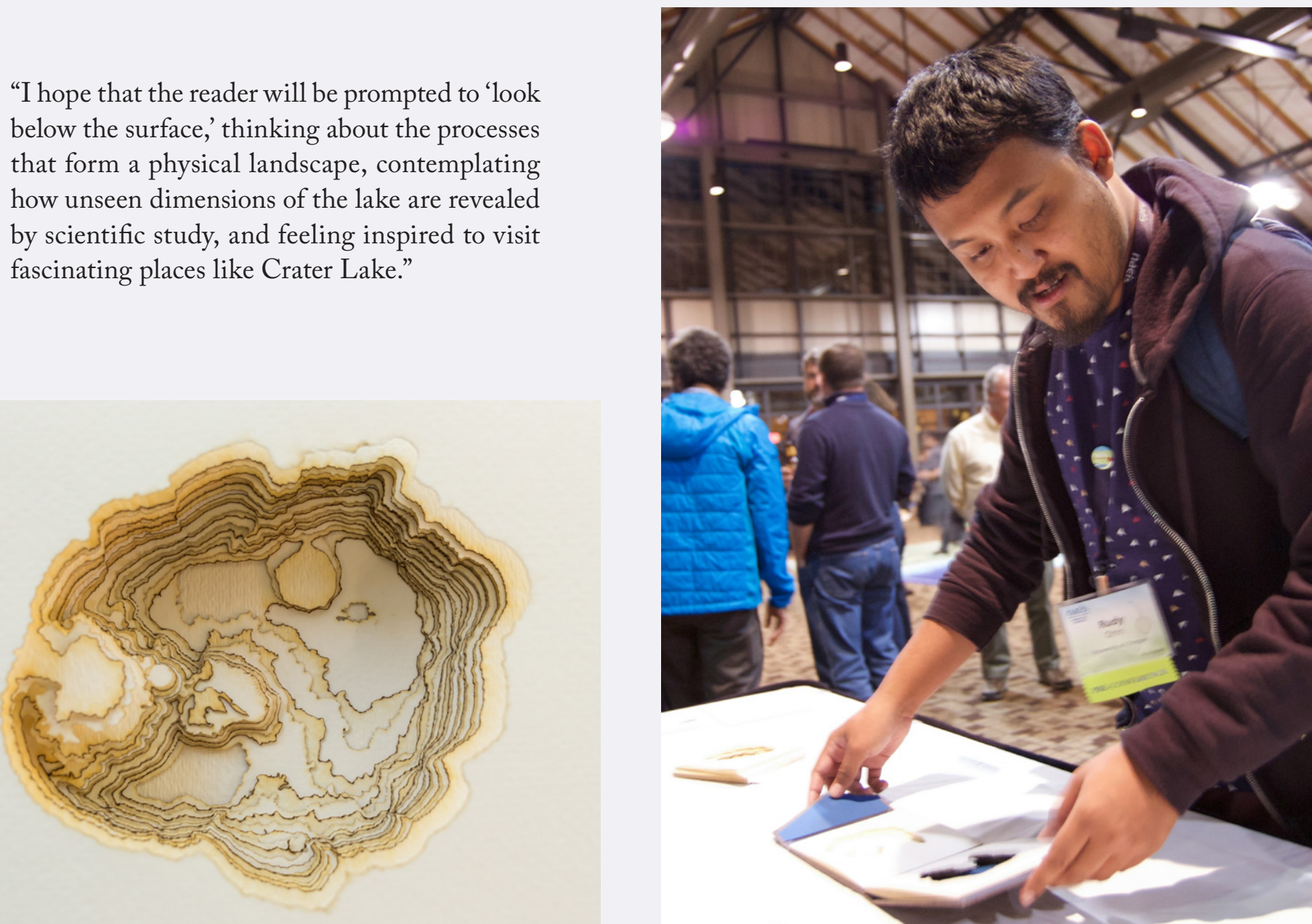

Photo by Charles P. Rader

Photo by Dylan Moriarty 


\section{BALANCEPLANET}

Hans van der Maarel and Mac Reijers. 2015. Printed spandex, rubber, air. 30"×30".

"You can't help but play with the BalancePlanet! It's meant to be used, to be touched, to be spun around. Thanks to its bright colors both young and old are attracted to it and can use it to learn about geography."
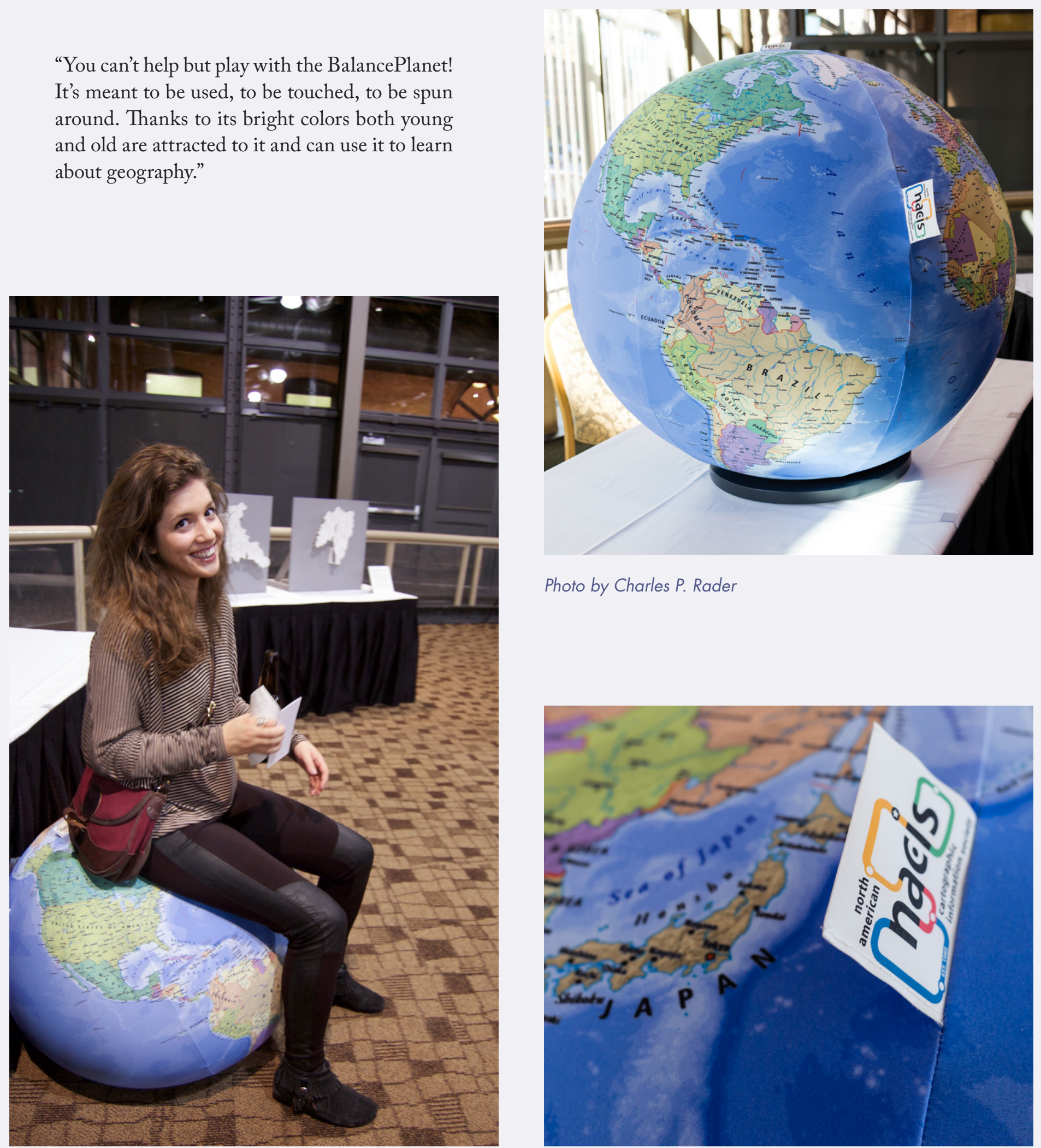

Photo by Charles P. Rader

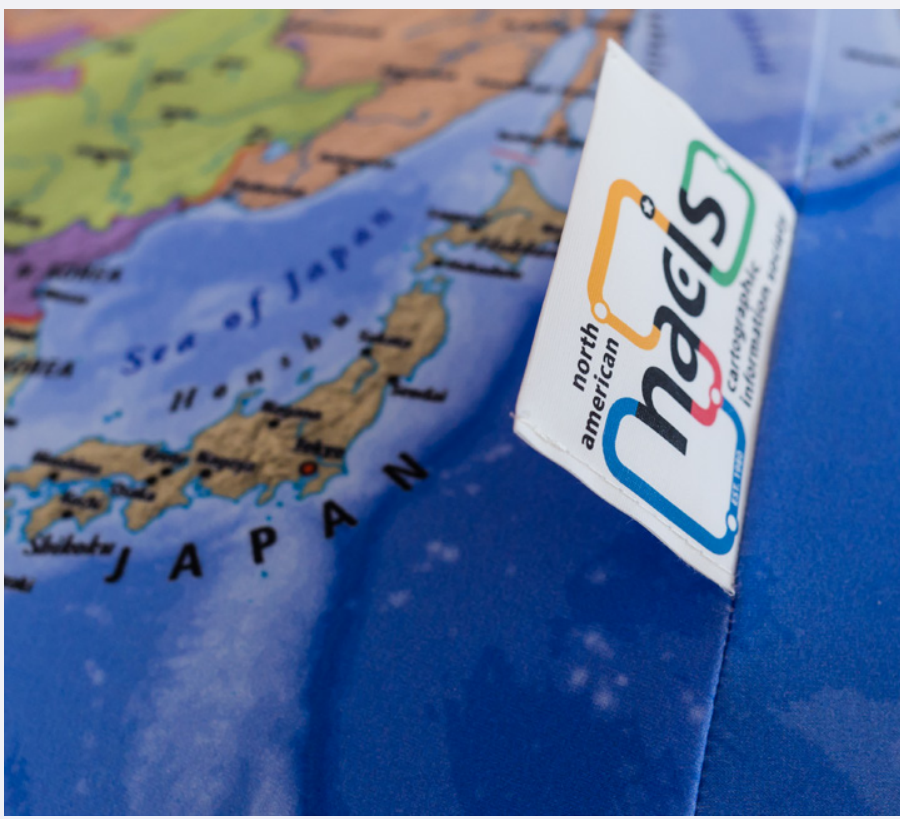

Photo by Dylan Moriarty

Photo by Charles P. Rader 
Matt Dooley. 2014. Ceramic. 50"×60".

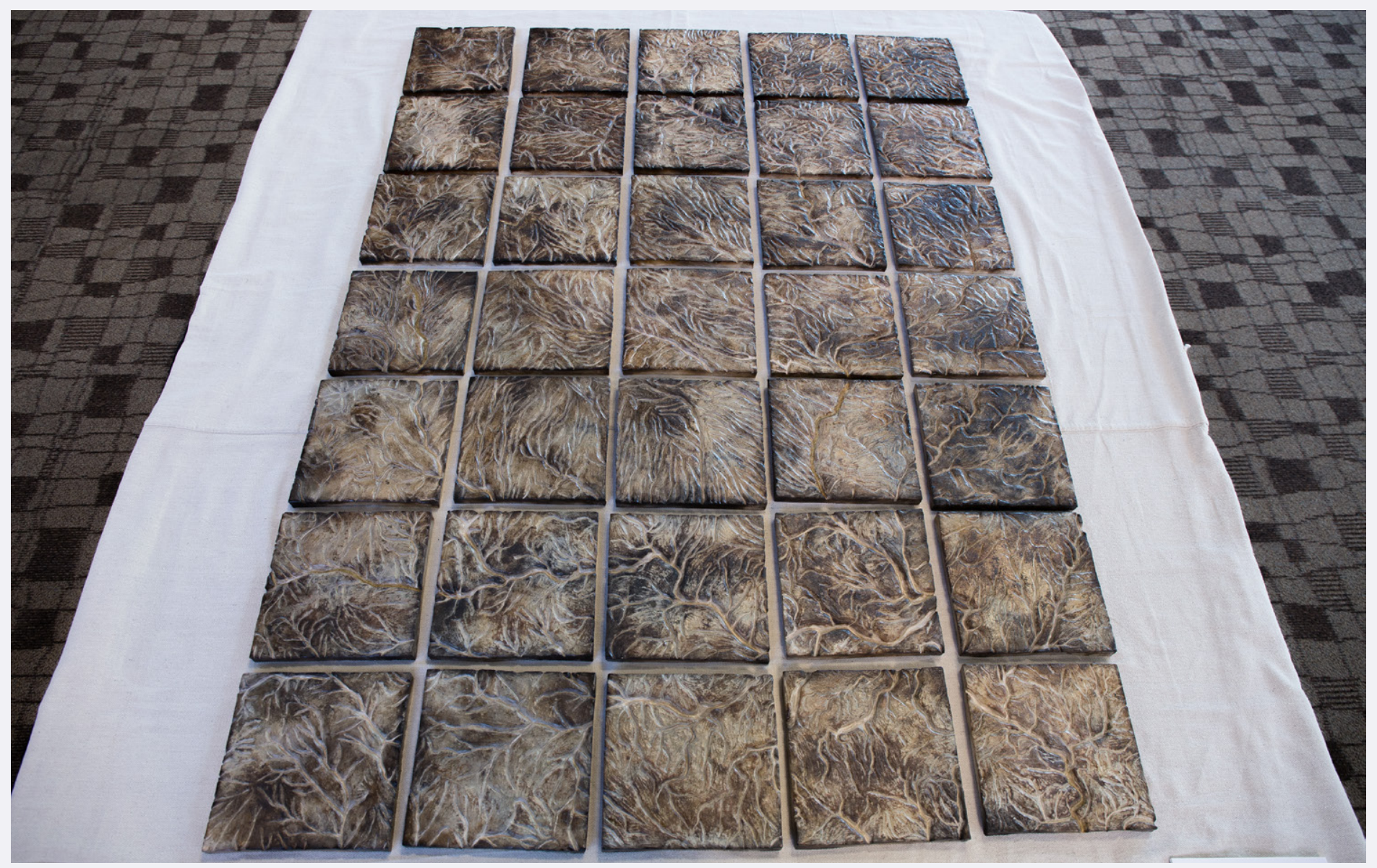

Photo by Charles P. Rader

"Working at a slower iterative pace has challenged my mapping practice in several ways. It provides time for contemplation about the act of mapping itself, as well as the places being represented."

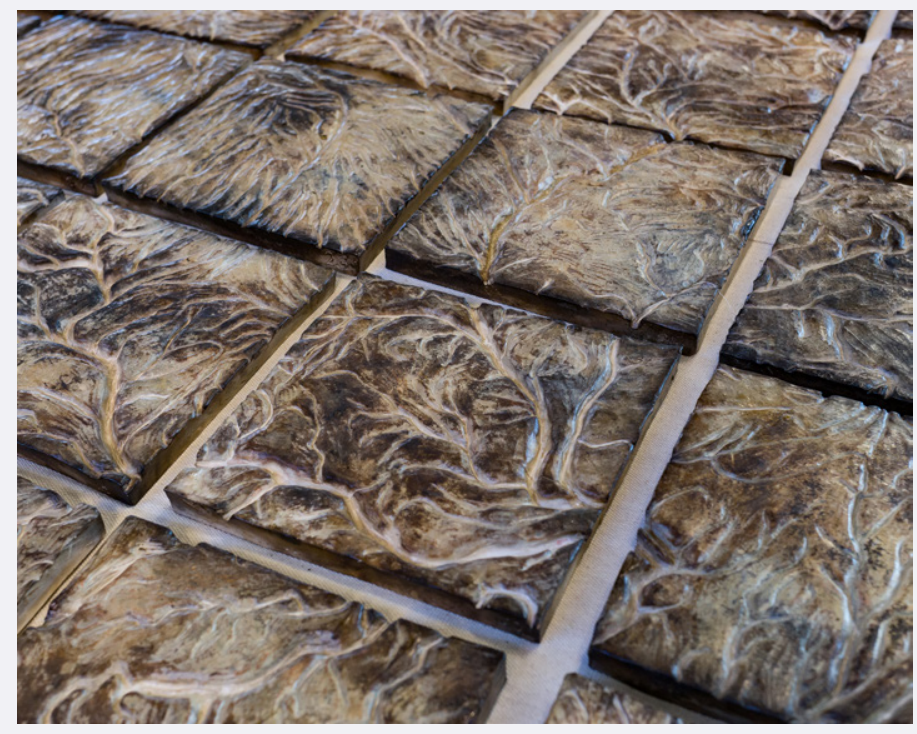

Photo by Charles P. Rader

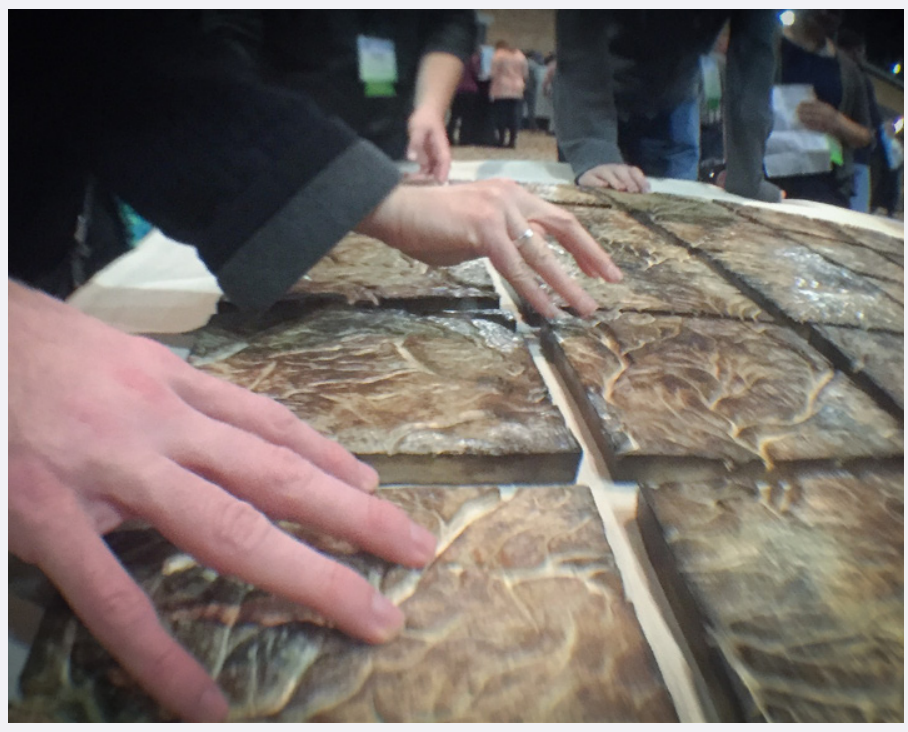

Photo by Matt Dooley 
Lauren Rosenthal. 2011. Hand-cut watercolor paper, wood, steel, paint. Left: Mohawk Watershed, 14.5"×21". Right: Upper Hudson Watershed, 13"×15".
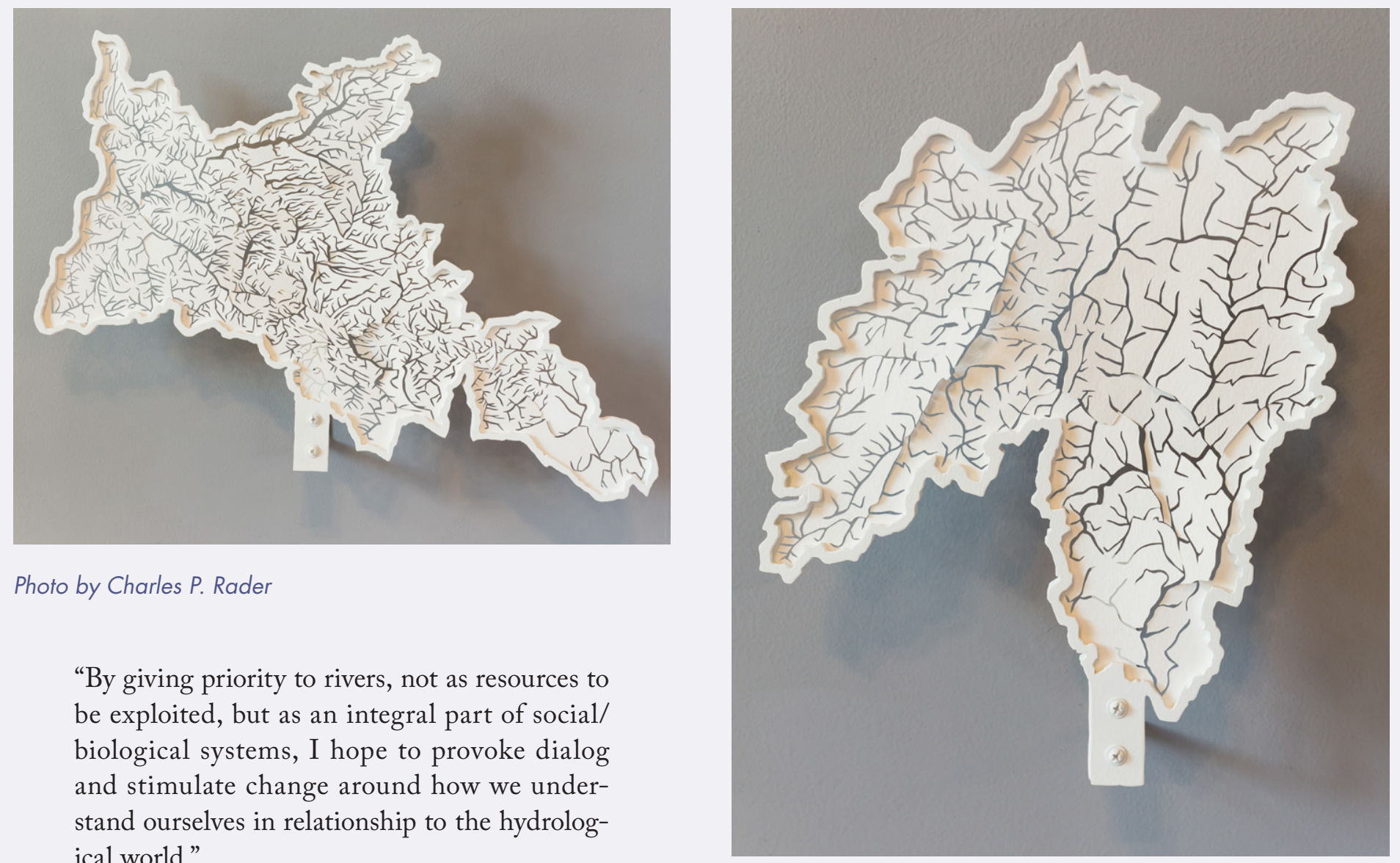

"By giving priority to rivers, not as resources to be exploited, but as an integral part of social/ biological systems, I hope to provoke dialog and stimulate change around how we understand ourselves in relationship to the hydrological world."

\section{PUBLIC GREEN/AREAS VERDES PÚBLICAS}

Lize Mogel. 2001. Silkscreen on Opallene. 48"×70".

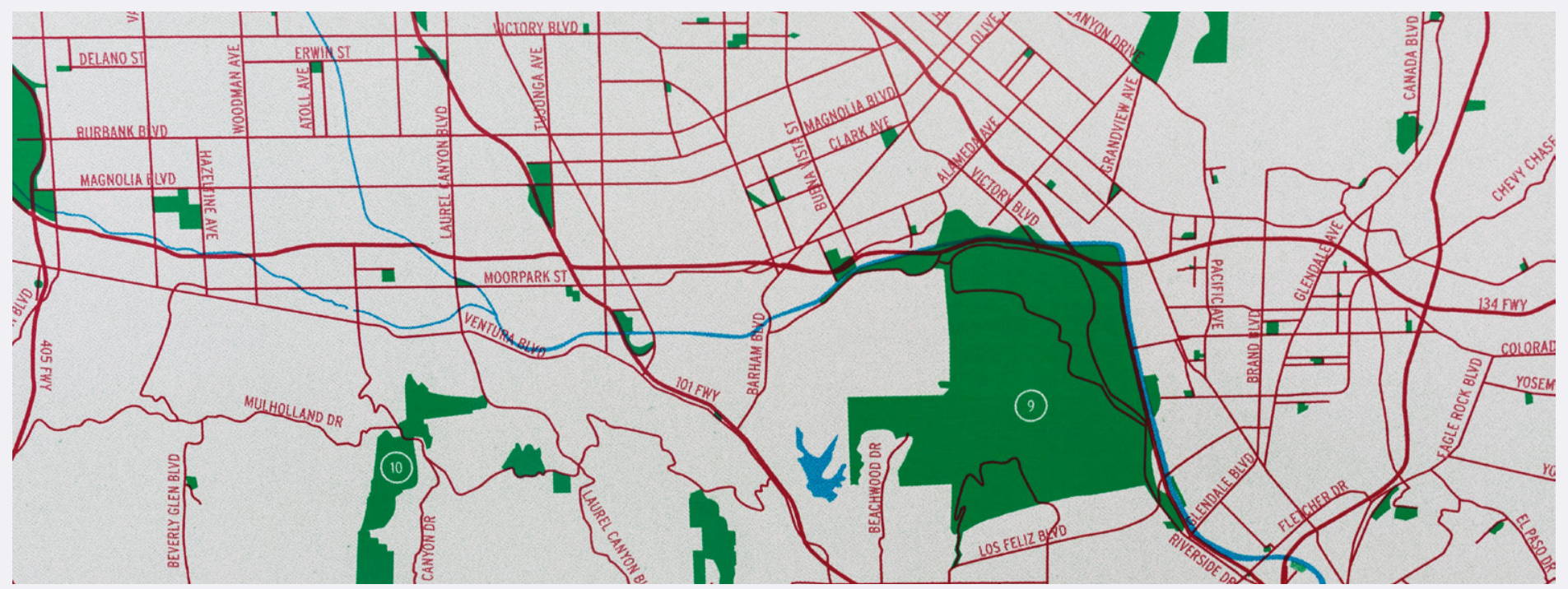

Photo by Charles P. Rader 
"For me, 'tangibility' and 'interaction' is about access - not just to information or ways of thinking about a place, but to the means to change the nature of place. In 2001, specialized cartographic knowledge about the city was inaccessible to most people."

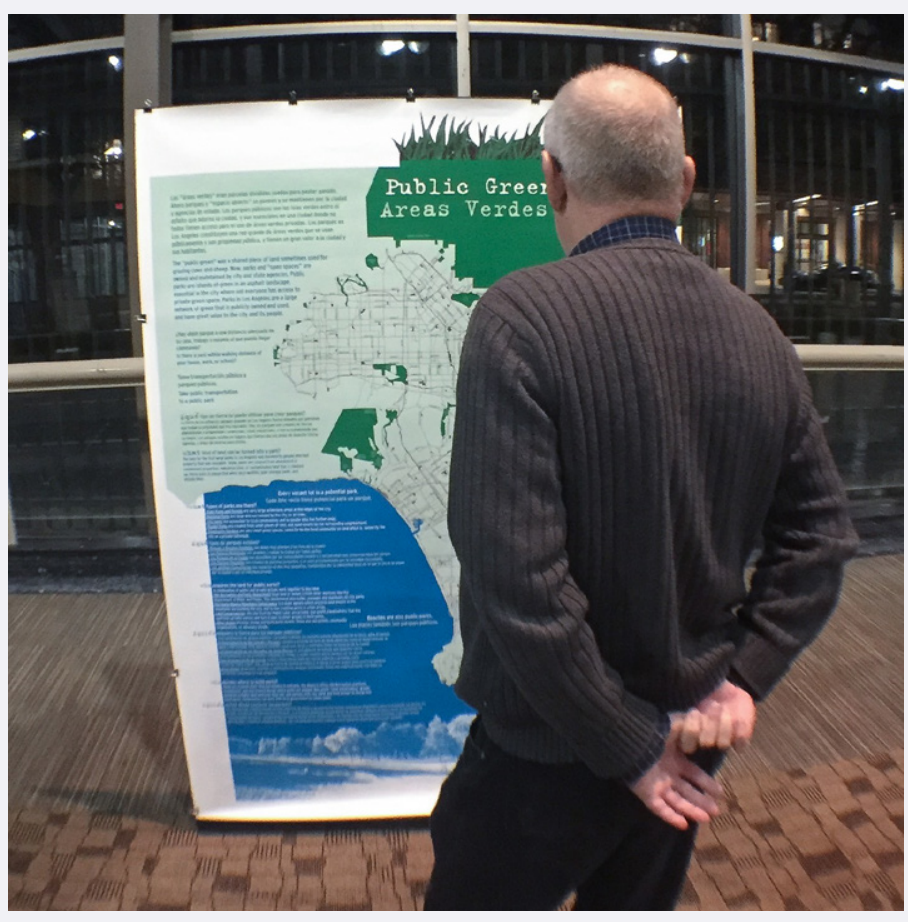

Photo by Matt Dooley

\section{PORTLAND BRIDGES AND PORTLAND BRIDGES II}

Nick Martinelli with Christopher Adams. 2014-2015. Screen print and letterpress on paper. Ea. 18"×12".

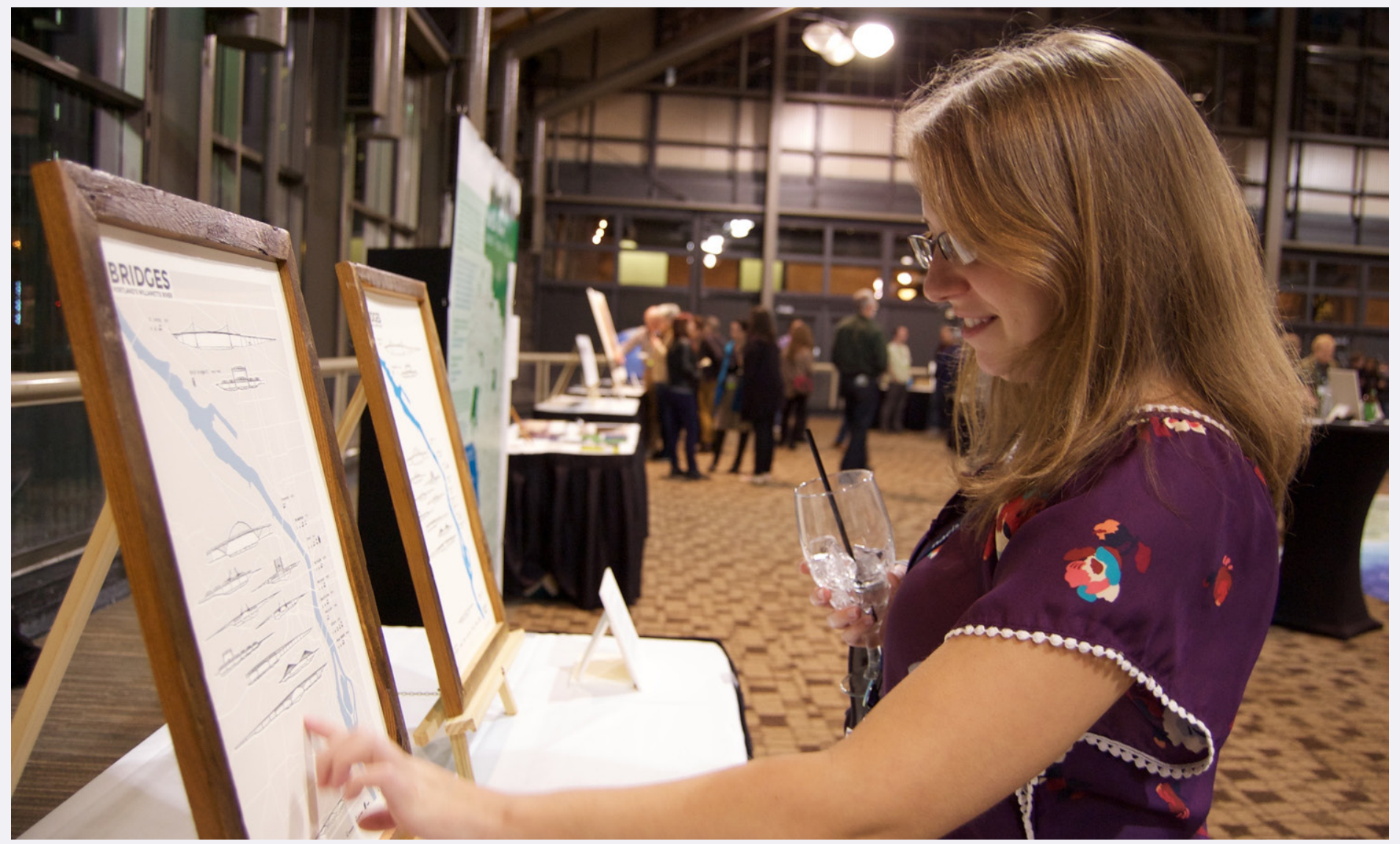

Photo by Dylan Moriarty 


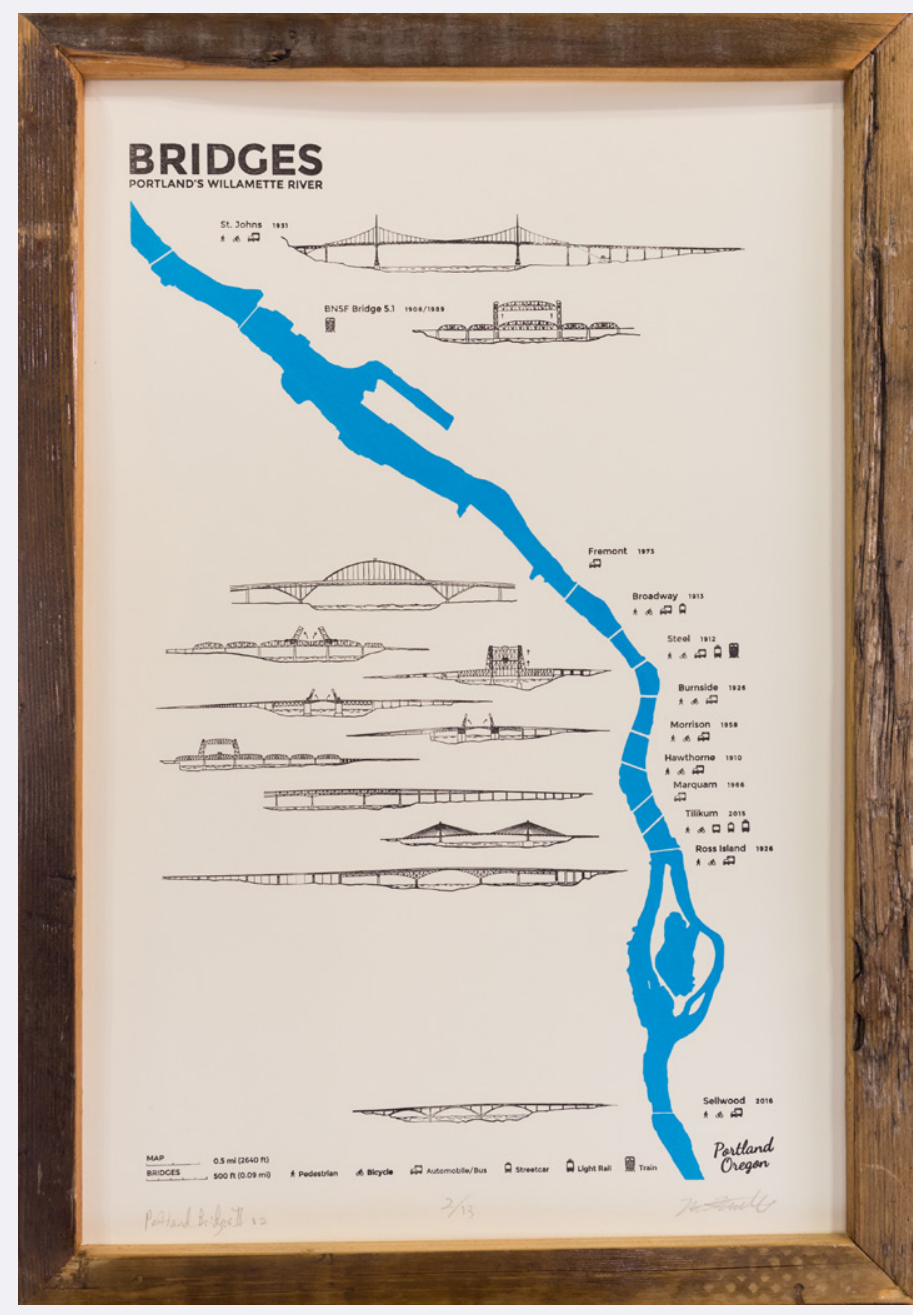

Photo by Charles P. Rader
"The Portland Bridge Map is based on the simple idea that most street maps do not convey the personality of bridges.... In the end, we achieved our goal of producing fine quality hand printed maps and rejuvenating a century-old letterpress machine.”

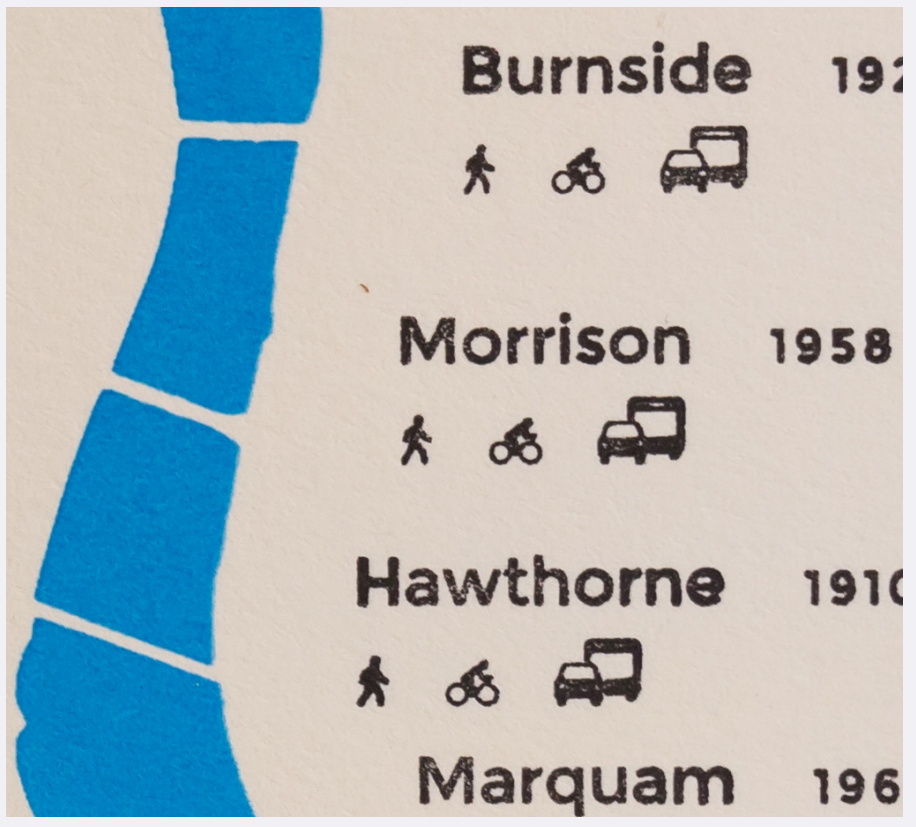

Photo by Charles P. Rader

\section{ACKNOWLEDGEMENTS}

We WOUld LIKE to extend our appreciation to Susan Peschel, Amy Griffin, Martha Bostwick and the NACIS Board of Directors, who helped make this exhibit possible. Thanks to Dylan Moriarty and Charlie Rader for their amazing camera work. A special thanks goes out to Kryssy Pease and Tom Crann from Minnesota Public Radio, who covered the exhibit in a thoughtful radio piece that stirred interest in the local Minneapolis community and beyond.

Visual Fields focuses on the appreciation of cartographic aesthetics and design, featuring examples of inspirational, beautiful, and intriguing work. Suggestions of works that will help enhance the appreciation and understanding of the cartographic arts are welcomed, and should be directed to the new incoming section editor, Matt Dooley: mathew.dooley@uwr.edu.

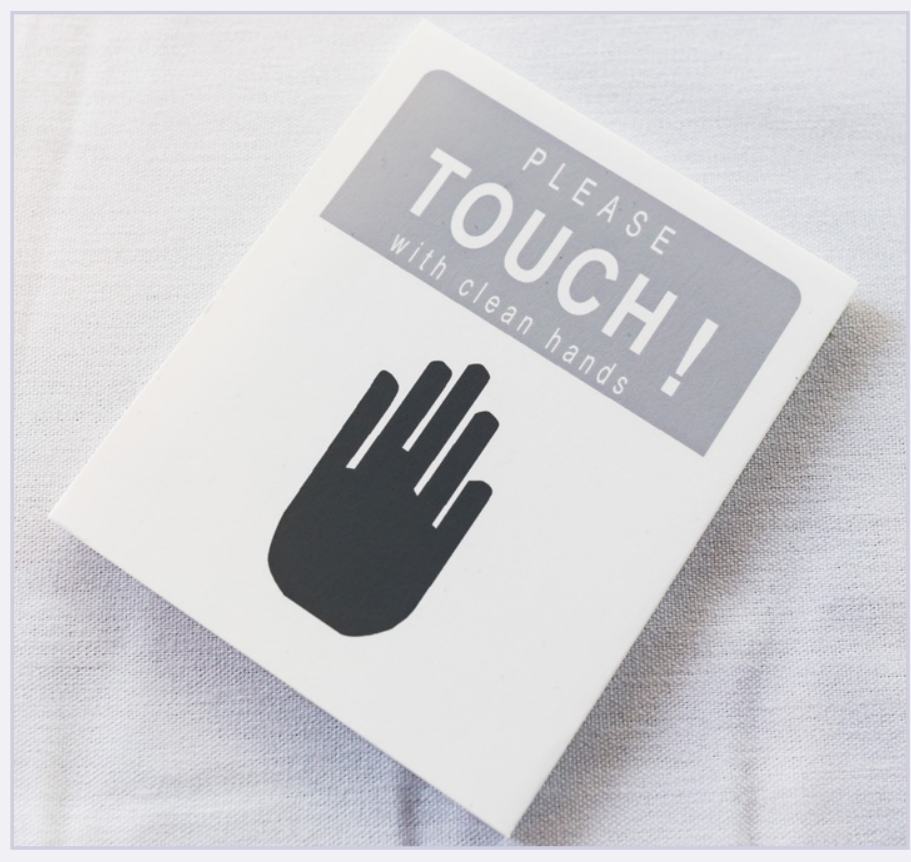

"Please touch!" Photo by Charles P. Rader 